\section{Socio-demographic Determinants of Poor Glycaemic Control among Type 2 Diabetes Mellitus (T2DM) Patients Attending Clinics at the Three Selected Health Facilities in Suva, Fiji in 2011-2016}

Pablo $\mathbf{C R}^{*}$, Masoud M , Donald $\mathbf{W}$ and Sabiha K

School of Public Health and Primary Care, Fiji National University, Suva, Fiji

*Corresponding author: Pablo CR, School of Public Health and Primary Care, Fiji National University, Suva, Fiji, Tel: +92937929122; E-mail: masoud.m@fnu.ac.fj

Received date: April 06, 2018; Accepted date: April 08, 2018; Published date: April 23, 2018

Copyright: (C) 2018 Pablo CR, et al. This is an open-access article distributed under the terms of the Creative Commons Attribution License, which permits unrestricted use, distribution, and reproduction in any medium, provided the original author and source are credited.

\begin{abstract}
Introduction and Aim:Diabetes is one of the largest health emergencies in the 21st century. In Fiji, type 2 diabetes mellitus (T2DM) is the number one cause of premature deaths and disability. The aim of this study was to determine the socio-demographic determinants of poor glycemic control among T2DM patients attending clinics at the three selected health facilities in Suva, Fiji.

Methods:This facility based 5-year retrospective folder audit among 338 randomly selected T2DM patient records registered between August 1, 2011 to August 1, 2016 from three selected health facilities in Suva, Fiji through proportionate sampling method and met the following inclusion criteria: T2DM adults >18 years; on treatment for $>1$ year; had $>4$ clinic visits and; had recent HbA1c result in 2017 . Glycemic level was assessed using the most recent $\mathrm{HbA} 1 \mathrm{c}$ level and poor glycemic control was defined as $\mathrm{HbA} 1 \mathrm{c}$ of $>7 \%$. Data analysis included both descriptive and inferential statistics using SPSS v. 22 to assess the independent variable's association with glycemic control. $P$ value $<0.05$ was considered significant.
\end{abstract}

Results:The 338 T2DM patients had a mean age of 56.5 years $(\mathrm{SD}=+9.9), 62.1 \%$ were $<60$ years old, $62.1 \%$ were females and $63.9 \%$ were of Fijian of Indian Descent (FID). The prevalence of poor glycemic control was $77.2 \%$. Mean $\mathrm{HbA} 1 \mathrm{c}$ was $8.6 \%(\mathrm{SD}=+2.04)$. In logistic regression analysis, T2DM patients $<60$ years had twice the chances of having poor glycemic control than their younger counterparts: odds ratio $(O R)=2.29 ; 95 \%$ confidence interval $(\mathrm{Cl}): 1.32,3.9 ; \mathrm{p}=0.003$. Those attending Suva diabetes Centre were found to be three times more likely to have poor glycemic control than those attending other diabetes clinics: $\mathrm{OR}=3.32 ; 95 \% \mathrm{Cl}: 1.22,9.04 ; \mathrm{p}=0.019$.

Conclusion:This study found a significantly high proportion of poorly controlled T2DM patients. Younger patients and those attending Suva Diabetes Centre were significant socio-demographic determinants of poor glycemic control. Health care workers dealing with T2DM patients should consider socio-demographic factors associated with glycemic control for a more patient-centered diabetes care.

Keywords: T2DM; Socio-demographic; Determinants; Glycaemic control; Fiji

\section{Introduction}

Diabetes is "one of the largest global health emergencies in the $21 \mathrm{st}$ century" [1,2]. In 2017, the International Diabetes Federation (IDF) estimated 424.9 million people $20-79$ years globally are suffering from diabetes where 1 in 11 people are affected by the disease with a prevalence rate of $8.8 \% ; 1$ in 2 adults is undiagnosed (212 million); and $12 \%$ of global health expenditure is spent on diabetes (USD727 billion). It is the second leading cause of years of life lost to premature death and the fourth leading cause of years lived with disability [3].

T2DM, which is the most common type of diabetes and the focus of this study is defined as a chronic medical condition that occurs when the body cannot produce enough insulin or cannot use insulin in adults [4-7]. A diagnosis of T2DM is made when a fasting blood sugar (FBS) level is $>7.0 \mathrm{~m} \mathrm{~mol} / \mathrm{L}$ or HbAlc of $>6.5 \%$ [12-16]. Good glycemic control in T2DM which is defined as FBS level of $4-6 \mathrm{~m}$ $\mathrm{mol} / \mathrm{L}$ or HbAlc of $<7 \%$ [5-7] is the center of diabetes management in order to prevent or delay onset of complications . Poor glycemic control among T2DM may cause blindness, cardiovascular disease, kidney failure, lower limb amputation and several other long term complications that impact significantly on quality of life [6-10].

The small Pacific Island Countries and Territories (PICTs) is home to the top six countries in the world with the highest diabetes prevalence rates in 20171 where diabetes prevalence rate of $40 \%$ is common with high rates of complications and poor clinical outcomes with over 70\% of T2DM patients not meeting glycemic control [11]. In Fiji, diabetes is the number one cause of disease specific mortality, most premature death and health problem causing the most disability in 2005 which remained unchanged in 2016 [12]. T2DM has a prevalence rate of $15.6 \%$ in 2011 and is projected to rise in 2020 to $19.3 \%$ driven by rising obesity with consequences for premature mortality and reduced life expectancy $[13,14]$ It accounts for $19.7 \%$ of all deaths with a mortality rate of 151.8 per 1,000 population and hospital admission rate due to complications of 134.5 per 1,000 admissions [15].

Most studies identified that socio-demographic characteristics associated with glycaemic control include: age, gender, ethnicity, 
educational level, family history, employment status, socio-economic status, housing, food security, cultural beliefs and practices, geographical locations, health literacy, social support and religious beliefs [16-20].

There have been no current published and peer reviewed research studies conducted in Fiji on the association of socio-demographic factors to glycemic control among T2DM patients. So the aim of this retrospective study was to determine the proportion of poor glycemic control level and its socio-demographic determinants among T2DM adults attending clinics at Suva health centers in 2011-2016. Knowing these different socio-demographic determinants of poor glycemic control in T2DM patients will add new insights and knowledge on the needs of T2DM patients which are key to developing effective evidence-based management and control strategies for these patients as well as ensure efficiency and effectiveness of diabetes clinics and special outpatient department (SOPD) clinics in Fiji.

\section{Methodology}

This was a five year retrospective medical audit using the medical records of T2DM adult patients $>18$ years old registered between August 1, 2011 to August 1, 2016 conducted at three randomly selected health centers in Suva, Fiji. Those that met the following inclusion criteria were included in the study: T2DM adults $>18$ years old; has the recent $\mathrm{HbA1c}$ test available in 2017; has been on treatment for $>1$ year; and has been attending diabetes clinic for $>4$ visits prior to the recent HbAlc was taken. The exclusion criteria for this study include those who did not meet the above inclusion criteria, type 1 diabetes patients and those with incomplete records (medical information and blood results).

A proportional sampling method was used to calculate the sample size using the prevalence rate of poor glycemic control among T2DM in Fiji which is $32.2 \%$. 21 A sample size $(n=354)$ which was allocated proportionately among the three selected health centers, was calculated using a $5 \%$ margin of error and $95 \%$ confidence interval (CI), with $32.2 \%$ proportion and adjusted by a factor of $10 \%$ of incomplete medical records. A systematic random sampling method was used to select the participants where every third (3rd) patient folder was chosen from the register of each of the selected health center. Out of the total calculated sample of 354, only 338 (with a 95 percent response rate) met the inclusion criteria which were distributed as 50 samples from Lami Health Centre, 132 samples from Suva Diabetes Centre and 156 samples from Valelevu Health Centre. A pre-tested data collection form was used in this study.

The dependent variable in this study was glycemic control which was coded as either poor or good. Poor glycemic control was defined as a mean $\mathrm{HbAlc}$ of $>7 \%$ while good glycaemic control was defined as mean HbAlc of $<7 \%$ during the study period [4-7]. The patient's most recent $\mathrm{HbAlc}$ was the parameter used to measure glycaemic control [19,21-23]. The independent variables used in this study were age, gender, ethnicity, geographical location and health facility.

The International Business Machine (IBM) Statistical Package for Social Sciences (SPSS) version 22.0 software was used to analyze the data. Continuous variables were described using the mean, median, standard deviation and range values while the qualitative and categorical variables were described using frequency and percentage tables. Descriptive statistics were used to determine the glycemic control level among T2DM patients. Logistic regression analyses were performed to assess the effect of independent variables on glycaemic control. $\mathrm{P}<0.05$ has been considered as the level of significance.

Bivariate logistic regression analysis was conducted to determine the association of each independent variable (the socio-demographic factors) with the dependent variable (glycaemic control: poor $>7 \%$, good $<7 \%$ ). To correctly predict the category of outcome for individual factors, a model was created to include all the predictor variables (socio-demographic factors) that were useful in predicting the response variable. Binary logistic regression analysis was used to eliminate confounding effect as there were more than one independent variables. A forward stepwise logistics regression was used starting with the constant-only model and adding variables one at a time. The overall significance of the model was tested using Omnibus test while Hosmer and Lemeshow test was used to determine the adequacy of the model and its goodness of fit. The receiver operating characteristic (ROC) curve was used to evaluate the model fit.

Ethics approval were obtained from the Fiji National University College Health Research Ethics Committee (CHREC) and the Fiji National Health Research Ethics and Review Committee (FNHRERC) based at Fiji Ministry of Health and Medical Services. After both the ethics committees approval were received, written approvals were obtained from the medical officers in-charge of the selected health center's and the Permanent Secretary for Health and Medical Services to collect data from the patient's folders before commencing the study.

\section{Results}

Three hundred fifty four (354) T2DM patient's clinic records were considered eligible for this study through proportionate sampling method. Sixteen (16) were excluded due to incomplete records; hence, data were collated from 338 T2DM patient's records that were included in the analysis ( $95 \%$ response rate).

\section{Socio-demographic Characteristics of T2DM Patients Attending Clinics at Three Selected Health Centres in Suva, Fiji in $2011-2016$}

The T2DM patients in this study were composed of 200 females (59.2\%) and 138 males (40.8\%). The mean age for all T2DM patients was 56.5 years $(S D=+9.9)$ and ranged from 30 years to 82 years. Approximately, two-thirds (62.1\%) of the T2DM patients were less than 60 years of age while $37.9 \%$ were those 60 years old and over. Majority of T2DM patients were Fijian of Indian Descent (FID), $63.9 \%$. The I-Taukei (IT) which comprise more than half (57\%) of Fiji's total population and the minority Fijian of other descent (FOD) comprising of Rotumans, part-Europeans, Chinese, etc comprised $25.7 \%$ and $10.4 \%$, respectively. Majority lives in urban settings $(77.5 \%)$ while $12.1 \%$ and $10.4 \%$ live in rural and informal settings, respectively. Almost half of the participants $(46.1 \%)$ were attending diabetes clinic at Valelevu Health Centre while $39.1 \%$ and $14.8 \%$ were attending Suva Diabetes Centre and Lami Health Centre, respectively (Table 1).

\begin{tabular}{|l|l|}
\hline & \\
\hline Socio-demographic characteristics $(n=338)$ & $n(\%)$ \\
\hline Gender & \\
\hline Female & $200(59.2)$ \\
\hline Male & $138(40.8)$ \\
\hline
\end{tabular}


Citation: Pablo CR, Masoud M, Donald W and Sabiha K(2018) Socio-demographic Determinants of Poor Glycaemic

Control among Type 2 Diabetes Mellitus (T2DM) Patients Attending Clinics at the Three Selected Health Facilities in Suva, Fiji in 20112016. J Diabetic Complications Med 3: 120. doi:10.4172/2475-3211.1000120

Page 3 of 6

\begin{tabular}{|l|l|}
\hline Age in years: mean $\left({ }^{*} \mathrm{SD}\right)=56.5(+9.9)$ & \\
\hline$<60$ & $210(62.1)$ \\
\hline$>60$ & $128(37.9)$ \\
\hline Ethnicity & $87(25.7)$ \\
\hline${ }^{* *}$ IT & $216(63.9)$ \\
\hline${ }^{* *} \mathrm{FID}$ & $35(10.4)$ \\
\hline${ }^{* *}$ FOD & \\
\hline Geographical location & $41(12.1)$ \\
\hline Rural & $262(77.5)$ \\
\hline Urban & $35(10.4)$ \\
\hline Informal settlement & \\
\hline Health Facility & $50(14.8)$ \\
\hline Lami Health Centre & $156(46.1)$ \\
\hline Valelevu Health Centre & $132(39.1)$ \\
\hline Suva Diabetes Centre & \\
\hline
\end{tabular}

Table 1: Socio-demographic characteristics of T2DM attending clinics at the three selected health centres in Suva, Fiji in $2011-2016$.

${ }^{*}$ SD- Standard Deviation, ${ }^{* *}$ IT - I-Taukei or indigenous Fijian ${ }^{\star * \star}$ FID - Fijian of Indian Descent, ${ }^{\star * * *}$ FOD - Fijians of Other ethnic Descent -Rotumans, Part-Europeans, Chinese and Fijian Citizen of other ethnic descent.

\section{Glycemic Control of T2DM Patients Attending Clinics at Three Selected Health Centres in Suva, Fiji in 2011-2016}

After reviewing the clinic records of 338 T2DM patients who were registered during the 5 year period in August 1,2011 to August 1,2016 and who were still attending clinic in 2017, the proportion of poor glycaemic control (HbAlc $>7.0 \%$ ) based on the patient's most recent HbAlc test result was $77.2 \%$ while only $22.8 \%$ had good glycaemic

control (HbA1C $<7.0 \%$ ) (Table 2). The mean $\mathrm{HbAlc}$ was $8.6 \%$ (SD= +2.04 ) and ranging from $5.0 \%$ to $16.6 \%$.

\begin{tabular}{|c|c|c|}
\hline Glycaemic Control & Frequency (n) & $\begin{array}{l}\text { Percentag } \\
\text { e (\%) }\end{array}$ \\
\hline Good $(\mathrm{HbA} 1 \mathrm{c}<7 \%)$ & 77 & 22.8 \\
\hline Poor $(\mathrm{HbA} 1 \mathrm{c}>7 \%)$ & 261 & 77.2 \\
\hline
\end{tabular}

Table 2: Proportion of Glycaemic control among the participants.

As shown in Table 3, the proportion of T2DM patients with poor glycemic control was greater in female than male gender at $45.3 \%$ and $31.9 \%$, respectively. More than half $(52.3 \%)$ of those with poor glycemic control were those less than 60 years of age. As regards ethnicity, almost half $(49.7 \%)$ of the T2DM patients who had poor glycemic control were FID while the IT and the FOD had $19.5 \%$ and $8.0 \%$ poor glycemic control, respectively. T2DM patients attending clinic at Suva Diabetes Centre had the highest proportion of poor glycaemic control (35.2\%), followed by Valelevu Health Centre (31.1\%) and Lami Health Centre (10.9\%).

Logistic regression analysis of T2DM patient's socio-demographic characteristics on HbA1c control showed that T2DM patients $<60$ years old had twice the chances of having poor.

glycaemic control compared to their older counterparts: Odds Ratio $(\mathrm{OR})=2.29 ; 95 \%$ Confidence Interval $(\mathrm{CI})=1.32,3.97 ; \mathrm{p}=0.003$. Those T2DM patients attending diabetes clinic at Suva Diabetes Centre were three times more likely to have poor glycemic control compared to those attending other diabetes clinics: $\mathrm{OR}=3.32 ; 95 \% \mathrm{CI}=1.22$, 9.04; $\mathrm{p}=0.019$ (Table 3 ). The regression model was statistically significant, $\mathrm{X} 2=34.5, \mathrm{p}=0.001 \quad(<0.05), \mathrm{df}=8$. The model explained $14.8 \%$ (Nagelkerke R2) of the variance in those with poor glycaemic control and correctly classified $77.4 \%$ of the cases with predicted probability of $71.1 \%$ (area under the receiver operating characteristics (ROC) curve).

\begin{tabular}{|c|c|c|c|c|c|}
\hline \multirow[t]{3}{*}{ Socio-demographic determinant } & \multicolumn{2}{|c|}{ Glycaemic level } & $\begin{array}{l}\text { Crude } \\
{[95 \% \mathrm{Cl}]}\end{array}$ & \multirow{3}{*}{$\begin{array}{l}\text { Adjusted } \\
{[95 \% \mathrm{Cl}]}\end{array}$} & \\
\hline & ${ }^{*}$ Good & ${ }^{* *}$ Poor & $p$ value & & \\
\hline & $\mathrm{n}(\%)$ & $\mathrm{n}(\%)$ & & & \\
\hline \multicolumn{6}{|l|}{ Gender } \\
\hline Male & $30(8.9)$ & $108(31.9)$ & 1 & 1 & \\
\hline Female & $47(13.9)$ & $153(45.3)$ & $\begin{array}{l}0.90 \\
1.52]\end{array} \quad[0.54$ & $0.85[0.49,1.49]$ & 0.578 \\
\hline \multicolumn{6}{|l|}{ Age in years } \\
\hline$<60$ & $33(9.8)$ & $177(52.3)$ & $\begin{array}{l}2.81 \\
4.73]\end{array} \quad[1.67$, & $2.29[1.32,3.97]$ & $* * * .003$ \\
\hline$>60$ & $44(13.0)$ & $84(24.9)$ & 1 & 1 & \\
\hline
\end{tabular}


Citation: Pablo CR, Masoud M, Donald W and Sabiha K (2018) Socio-demographic Determinants of Poor Glycaemic

Control among Type 2 Diabetes Mellitus (T2DM) Patients Attending Clinics at the Three Selected Health Facilities in Suva, Fiji in 20112016. J Diabetic Complications Med 3: 120. doi:10.4172/2475-3211.1000120

Page 4 of 6

\begin{tabular}{|c|c|c|c|c|c|c|}
\hline Ethnicity & & & & & & \\
\hline alt & $21(6.2)$ & $66(19.5)$ & 1 & & 1 & \\
\hline bFID & $48(14.2)$ & $168(49.7)$ & $\begin{array}{l}1.13 \\
2.03]\end{array}$ & {$[0.63$} & $1.34[0.68,2.66]$ & 0.433 \\
\hline cFOD & $8(2.4)$ & $27(8.0)$ & $\begin{array}{l}1.09 \\
2.76]\end{array}$ & {$[0.43$} & $1.17[0.43,3.20]$ & 0.758 \\
\hline \multicolumn{7}{|l|}{ Geographical location } \\
\hline Rural & $7(2.1)$ & $34(10.0)$ & 1 & & 1 & \\
\hline Urban & $62(18.3)$ & $200(59.2)$ & $\begin{array}{l}0.66 \\
1.57]\end{array}$ & {$[0.28$} & $0.63[0.22,1.82]$ & 0.393 \\
\hline Informal Settlement & $8(2.4)$ & $27(8.0)$ & $\begin{array}{l}0.69 \\
2.16]\end{array}$ & {$[0.22$} & $0.58[0.15,2.30]$ & 0.44 \\
\hline \multicolumn{7}{|l|}{ Health Facility } \\
\hline Lami Health Centre & $13(3.9)$ & $37(10.9)$ & 1 & & 1 & \\
\hline \multicolumn{7}{|l|}{ Suva Diabetes Centre } \\
\hline & $13(3.9)$ & $119(35.2)$ & $\begin{array}{l}3.22 \\
7.55]\end{array}$ & {$[1.37$} & $3.32[1.22,9.04]$ & ${ }^{* * *} .019$ \\
\hline \multicolumn{7}{|l|}{ Valelevu Health Centre } \\
\hline & $51(15.0)$ & $105(31.1)$ & $\begin{array}{l}0.72 \\
1.48]\end{array}$ & {$[0.35$} & $0.85[0.34,2.14]$ & 0.723 \\
\hline
\end{tabular}

Table 3: Socio-demographic determinants associated with poor glycaemic control among T2DM attending clinics at the three selected health centres in Suva, Fiji in 2011 - 2016.

${ }^{*}$ Good glycaemic level $(\mathrm{HbAlc}<7 \%)$, ** Poor glycaemic level $(\mathrm{HbA1C}>7 \%),{ }^{* * *}$ Significant $\mathrm{p}<0.05$, aIT I-Taukei (Indigenous Fijians), bFID - Fijian Indian Descent, cFOD - Fijian of Other Descent (Rotumans, Part-Europeans, Chinese, etc)

\section{Discussion}

The main objective of this study was to determine the sociodemographic factors associated with glycaemic control among T2DM patients. Knowledge of these factors will assist health care workers identify those who are at risk of having poor glycaemic control and will be used to provide targeted interventions. To determine the sociodemographic determinants of poor glycaemic control, a quantitative study using a 5-year retrospective folder audit was conducted on T2DM patient records attending diabetes clinics at the three selected health facilities in Suva, Fiji in 2011 - 2016.

The results of this study showed a mean $\mathrm{HbAlc}$ of $8.6 \%(\mathrm{SD}=+2.4)$ among T2DM patients attending the three selected urban health facilities in Suva, Fiji. This was higher compared to the mean HbAlc of $6.5 \%(\mathrm{SD}=+1.3)$ result of the study conducted by Brian et al among 1,131 T2DM patients, living in eight provinces of Viti Levu the main island of Fiji as part of the HbAlc data collected during the Fiji Eye Health Survey 2009 (FEHS2009) [24]. Majority ( $\mathrm{n}=261)$ of the T2DM patients in this study which constitute $77.2 \%$ had poor glycaemic control according to the recommended HbA1C target levels of $<7.0 \%$ to achieve good glycaemic control in order to prevent diabetic complications [4-8]. This finding is similarly shown in previous studies conducted in Fiji [25] and other parts of the world especially in low and middle income countries [11,26-31]. This finding is more than twice the result of the Fiji NCD Steps survey conducted in 2002 which showed poor glycaemic control of 32.2\% among T2DM patients 25-64 years who were previously diagnosed with T2DM and were taking medications [21]. However, the 2002 survey used fasting blood sugar (FBS) instead of HbAlc as measure of glycaemic control. Also, this proportion of poor glycaemic control is higher than those estimated in developed countries which ranged from $25 \%$ to $53 \%[16,26,32,33]$. Despite the development of evidence-based clinical practice guidelines and its recommendation for stringent glycaemic control to prevent complications, over $60 \%$ of T2DM patients are still not reaching the recommended glycaemic goals [34]. This could be due to vast host of factors that are associated with glycaemic control which are beyond the patient's and the health care worker's control.

This study found using logistic regression analysis that age and health facility were significant factors to poor glycaemic control. The mean age for this study was 56.5 years $(\mathrm{SD}=+9.9)$ and those T2DM patients less than 60 years old had twice the chances of having poor glycaemic control $(\mathrm{OR}=2.29 ; 95 \% \mathrm{CI}=1.32,3.97 ; \mathrm{p}=0.003)$. This is similar to most studies which found that poor glycaemic control is common in younger age group $[29,30,32,35,36]$. This maybe because older T2DM patients in Fiji are more compliant to their clinic appointments and treatment with good family support. Younger T2DM patients, on the other hand, appear to have severe form of diabetes associated with a higher degree of insulin resistance, more rapidly increasing glucose levels, and worse glycaemic control that is more resistant to current treatment modalities [36,37]. Other studies found that poor glycaemic control is common among older T2DM 
patients due to co-morbidities and poor treatment adherence $[27,38]$ On the other hand, Ostgren et al and Kayar et al found no relationship between age and poor glycaemic control [39,40]. T2DM patients attending Suva Diabetes Centre have poorer glycaemic control $(\mathrm{OR}=3.22 ; 95 \% \mathrm{CI}=1.37,7.55 ; \mathrm{p}=0.019)$ compared to those attending the other two selected health centres. This may be attributed to the fact that Suva Diabetes Centre is a referral centre for uncontrolled T2DM patients. Most of the patients in these centre have uncontrolled and complicated diabetes. Once their diabetes is controlled and their complications treated, these T2DM patients are referred back to the health centre where they originally attended for follow-up.

In this study, there was no significant gender difference on poor glycaemic control. This is similar to the results of the study conducted by Kellow et al where they found no significant gender differences of poor glycaemic control between men and women [33]. Studies, however, have shown that poor glycaemic control is common in women than men $[27,35,41]$. While other studies found poor glycaemic control is common among men [42,43]. Most studies have found that ethnicity is highly associated with poor glycaemic control [21,27,28,44-46] due to multiple contributing factors including biological, clinical, health system and social factors [44]. In this study, ethnicity was not significantly associated with poor glycaemic control that is similar to other studies which found that ethnicity is no longer a factor associated with poor glycaemic control after taking other factors into account $[26,33,47]$. Similarly, some studies found that geographical location is associated with poor glycaemic control [48-52]. The reasons for this clustering of poorly controlled diabetes in a hot spot location include socio-economic deprivation, higher proportion of older population with co-morbidities and that people with similar risk factors, age and cultural backgrounds live in close proximity [49]. In this study, geographical location was not a significant factor.

This study has a number of strengths that are worth noting. First, the results of this study provides an updated proportion of glycaemic control among T2DM diabetes patients attending clinics in Suva, Fiji. Second, this study identified socio-demographic factors that were significant determinants of poor glycaemic control which are key to developing effective evidence-based diabetes care and control strategies and policies.

Since this study was conducted on secondary data taken from T2DM patient's folders, it has some limitations in terms of incomplete clinic and non-clinic documentation. Second, this study was conducted in an urban setting. Selection of T2DM patients in rural settings and in remote areas might shed more light on other sociodemographic determinants of poor glycaemic control in other parts of the country. Third, although the sample size of this study was adequate, the diversity of the sample in terms of ethnicity was not fully proportional and represented where the Fijian of Indian descent were over represented in this study.

\section{Conclusion}

Diabetes is one of the largest global health emergencies in the 21st century, the second leading cause of year's life lost to premature death and the fourth leading cause of years lived with disability. T2DM which constitute 90 to 95 percent of people living with diabetes is the main focus of this study. In Fiji, T2DM has a high prevalence, mortality and admission rates due to complications. Despite remarkable progress in terms of development of numerous effective diabetes management and interventions, significant gaps still exist between knowledge gained through research and clinical practice to support lasting healthprotective behavioural changes T2DM patients need to achieve good glycaemic control and hence, prevent complications. This 5-year retrospective study aimed to determine the proportion of poor glycaemic control and its associated socio-demographic factors among T2DM patients attending clinics at the three selected health centres in Suva Fiji.

The results of this study showed $77.2 \%$ of T2DM patients attending clinics at the three selected health facilities in Suva, Fiji have poor glycemic control. Logistic regression analysis of the socio-demographic characteristics to glycemic control found that younger T2DM $<60$ years had twice the chances of having poor glycemic control compared to their older counterparts while those attending Suva Diabetes Centre had three times more chances to be associated with poor glycaemic control than those attending other diabetes clinics.

This study recommends for health care workers managing T2DM patients to consider socio-demographic determinants of poor glycaemic control for a more effective diabetes interventions. Further studies to determine socio-demographic determinants of poor glycaemic control using a mixed methodology is recommended to further enhance the depth and scope of understanding of the health issue.

\section{References}

1. International Diabetes Federation Eighth edition (2017) IDF Diabetes Atlas. 11: 40-58.

2. Zimmet $P$ (2017) Diabetes and its drivers: the largest epidemic in human history? Clinical Diabetes and Endocrinology. 11: 3-1.

3. World Health Organization (2009) Global health risks: mortality and burden of disease attributable to selected major risks.

4. American Diabetes Association. Standards of medical care in diabetes (2017). Diabetes care. 35: 519-520.

5. Ministry of Health Government of Fiji (2012) Diabetes management guidelines 3rd ed. 2012.

6. World Health Organization (2006) Definition and diagnosis of diabetes mellitus and intermediate hyperglycaemia report of $\mathrm{WHO} / \mathrm{IDF}$ consultation.

7. International Diabetes Federation (2017) Recommendations for managing type 2 diabetes in primary care. International Diabetes Federation.

8. World Health Organization. Global report on diabetes (2016) World Health Organization.

9. Stratton IM, Adler AI, Neil HAW, Matthews DR, Manley SE, et al. (2000) Association of glycaemia with macrovascular and microvascular complications of type 2 diabetes (UKPDS 35): prospective observational study. BMJ. 321: 405-412.

10. Kline R, Kline BE (1998) Relation of glycaemic control to diabetic complications and health outcomes. Diabetes Care. 3: 39-43.

11. Tin ST, Lee CM, Colagiuri R (2015) A profile of diabetes in Pacific Island Countries and Territories. Diabetes Res Clin Pract. 107: 233-246.

12. Institute for Health Metrics and Evaluation (2016) Healthdata.org

13. Morell S, Lin S, Tukana I, Linhart C, Taylor R, et al. (2016) Diabetes incidence and projections from prevalence surveys in Fiji. Biomed Central. 14: 1-8.

14. Lin S, Tukana I, Linhart C, Morrel S, Taylor R, et al. (2016) Diabetes and obesity trends in Fiji over 30 years. J. Diabetes. 8: 533-543.

15. Ministry of Health and Medical Services Fiji (2016) Parliament of Fiji parliamentary paper no.79 of 2016. Suva Fiji: Ministry of Health and Medical Services. 
Citation: Pablo CR, Masoud Mohammadnezhad, Donald Wilson, Sabiha Khan (2018) Socio-demographic Determinants of Poor Glycaemic Control among Type 2 Diabetes Mellitus (T2DM) Patients Attending Clinics at the Three Selected Health Facilities in Suva, Fiji in 20112016. J Diabetic Complications Med 3: 120. doi:10.4172/2475-3211.1000120

Page 6 of 6

16. Le Blanc E, Rosales G, Kachroo S, Mukherjee J, Funk KL, et al. (2015) Do patient or provider characteristics impact management of diabetes?. The American Journal of Managed Care. 21: 597-606.

17. Brown AF, Ettner SL, Piette J, Weinberger M, Gregg E, et al. (2004) Socioeconomic position and health among persons with diabetes mellitus: a conceptual framework and review of the literature. Epidemiol Rev. 2004 26: 63-77.

18. Walker RJ, Gebregziabher M, Martin HB, Egede LE (2014) Relationship between social determinants of health and processes and outcomes in adults with type 2 diabetes: validation of a conceptual framework. BioMed Central Endocrine Disorders. 14: 14-82.

19. Haemoglobin A1C (poor control) (2017). United States Department of Health and Human Services Health Resources and Services Administration.

20. Abdulrehman MS, Woith W, Jenkins S, Kossman S, Hunter GL (2016) Exploring cultural influences of self-management of diabetes in coastal Kenya: an ethnography. Global Qualtiative Nursing Research. 3: 1-13.

21. Fiji Ministry of Health. Non-communicable Disease Steps Survey 2002 p. 32

22. Heisler M, Piette JD, Spencer M, Kieffer E, Vijan S (2005) The relationship between knowledge of recent $\mathrm{HbAlc}$ values and diabetes care understanding and self-management. Diabetes Care. 28: 816-22.

23. Nicholas J, Charlton J, Dregan A, Gulliford MC (2013) Recent HbAlc values and mortality risk in Type 2 diabetes population-based casecontrol study. PLoS ONE. 8: 7-6.

24. Brian G, Ramke L, Maher L, Page A, Szetu J (2010) The prevalence of diabetes among adults aged 40 years and over in Fiji. NZ Med J 123: 68-75.

25. Kumar K, Snowdon W, Ram S, Khan S, Cornelius M, et al. (2012 Descriptive analysis of diabetes-related amputations at the Colonial War memorial Hospital, Fiji, 2010-2012. Public Health Action Journal. 4: 155-158.

26. Jyun YY, Chia FM, Chao Y (2012) Medical appointment no shows associated with poor glycaemic control among Taiwanese aborigines. Australian Journal of Rural Health. 20: 317-318.

27. Abougalambou S, Suleiman A, Abougalambou A (2015) Glycaeted haemoglobin control among type 2 diabetes patients attending a teaching hospital in Malaysia. Saudi Journal of Medical Pharmaceutical Science. 15: 93-102.

28. Timothy G (2015) Factors influencing glycaemic control in diabetics at three community health centres in Johannesburg. Diabetes Research Clinical Practice. 13: 1-149.

29. Juarez D, Sentell T, Tokomaru S, Go R, Davis JW, et al. (2012) Preventing chronic disease - factors associated with poor glycaemic control. Hawaii. 15: 2-10.

30. Camara A, Balde N, Sorongu J, Kengne AP, Diallo MM, et al. (2015) Poor glycaemic control in type 2 diabetes in the south of the Sahara: the issue of limited access to an $\mathrm{HbAlc}$ test. Diabetes Research and Clinical Practice. 108: 187-192.

31. Adeniyi O, Yogeswaran P, Longo-Mbenza B, Goon DT, Ajay AI (2016) Cross-sectional study of patients with type 2 diabetes in OR Tambo district, South Africa. British Medical Journal. 16: 1-7.

32. De Pablos VP, Parhofer KG, Bradley C, Eschwege E, Gonder FL, et al. Current level of glycaemic control and its associated factors in patients with type 2 diabetes across Europe: data from the PANORAMA study. Clinical Endocrinology. 80: 47-56.

33. Kellow N, Savige G, Khalil H (2011) Predictors of poor glycaemic control during the initial five years post-diagnosis in rural adults with type 2 diabetes. Australian Journal of Rural Health. 19: 267-274.

34. Del PS, Felton AM, Munro N, Nesto R, Zimmet P, et al. (2005) Improving glucose management: ten steps to get more patients with type 2 diabetes to glycaemic goal. Int J Clin Pract. 59:1345-1355.
35. Cambra K, Galbete A, Forga L, Lecea O, Ariz JM, et al. (2016) Sex and age differences in the achievement of control targets in patients with type 2 diabetes: results from a population-based study in the South European region. Biomed Central Family Practice. 17: 1-7.

36. Burns N, Finucane FM, Hatunic M, Gilman M, Murphy M, et al. (2007) Early-onset type 2 diabetes in obese white subjects is characterized by a marked defect in beta cell insulin secretion, severe insulin resistance and a lack of response to aerobic exercise training. Diabetologica. 50: 1500-1508.

37. D'Adamo E, Caprio S (2011) Type 2 diabetes in youth: epidemiology and pathophysiology. Diabetes Care. 34: 161-165.

38. Basu R, Breda E, Oberg A, Powell CC, Man CD, et al. (2003) Mechanisms of the age-associated deterioration in glucose tolerance contribution of alterations in insulin secretion, action, and clearance. 52: 1738-48.

39. Ostgren CJ, Linblad U, Ramstan J, Melander A, Rastam L (2002) Glycaemic control, disease duration and beta-cell function in patients with Type 2 diabetes in a Swedish community. Skaraborg Hypertension and Diabetes Project. Diabetic Medicine. 19: 125-129.

40. Kayar Y, Ilhan A, Kayar NB, Unver N, Coban G, et al. (2017) Relationship between the poor glycemic control and risk factors, life style and complications. Biomed Res. 28: 1581-1586.

41. Sanal TS, Nair NS, Adhikari P (2011) Factors associated with poor control of type 2 diabetes mellitus: a systematic review and meta-analysis. J Diabetol. 3: 1-10.

42. Geer EB, Shen W (2009) Gender differences in insulin resistance, body composition and energy balance. Gen Med. 6: 60-75.

43. Raum E, Kramer HU, Ruter G, Rothenbacher D, Rosemann, et al. (2012) Medication non-adherence and poor glycaemic control in patients with type 2 diabetes mellitus. Diabetes Res Clin Pract. 97: 377-384.

44. Golden SH, Brown A, Cauley JA, Chin MH, Gary-Webb TL, et al. (2012) Health disparities in endocrine disorders: biological, clinical and nonclinical factors: an endocrine society scientific statement. J Clin Endocrinol Metab. 97: 1579-639.

45. Harris MI, Eastman RC, Cowie CC, Flegal KM, Eberhart MS (1999) Racial and ethnic differences in glycaemic control of adults with type 2 diabetes. Diabetes Care. 22: 403-408.

46. Negandhi PH, Ghouri N, Colhoun HM, Fischbacher CM, Lindsay RS, et al. (2013) Ethnic differences in glycaemic control in people with type 2 diabetes mellitus living in Scotland. PLoS ONE. 8: 83-92.

47. Benoit S, Fleming R, Philis TA, Ji M (2005) Predictors of glycaemic control among patients with type 2 diabetes: a longitudinal study. Biomed Central Public Health. 5 36: 1-9.

48. Echeverria SE, Dietz-Roux AV, Link BG (2004) Reliability of self-reported neighborhood characteristics. J Urban Health. 81: 682-701.

49. Jiwa M, Godes O, Varho R, Mullan N (2015) Impact of geography on the control of type 2 diabetes mellitus: a review of geocoded clinical data from a general practice. BMJ.5: 1-8.

50. Smalls BL, Gregory CM, Zoller JS, Egede LE (2015) Direct and indirect effects of neighborhood factors and self-care on glycemic control in adults with type 2 diabetes. Journal of Diabetes and its Complications 29: 186-191.

51. Weng C, Coppini DV, Sonksen PH (2000) Geographic and social factors are related to increased morbidity and mortality rates in diabetic patients. Diabetic Med. 17: 612- 617.

52. Oti S, van de VS, Agyemang C, Kyobutungi C (2013) The magnitude of diabetes and its association with obesity in the slums of Nairobi, Kenya: results from a cross-sectional survey. European Journal of Tropical Medicine and International Health 18: 1520-1530. 